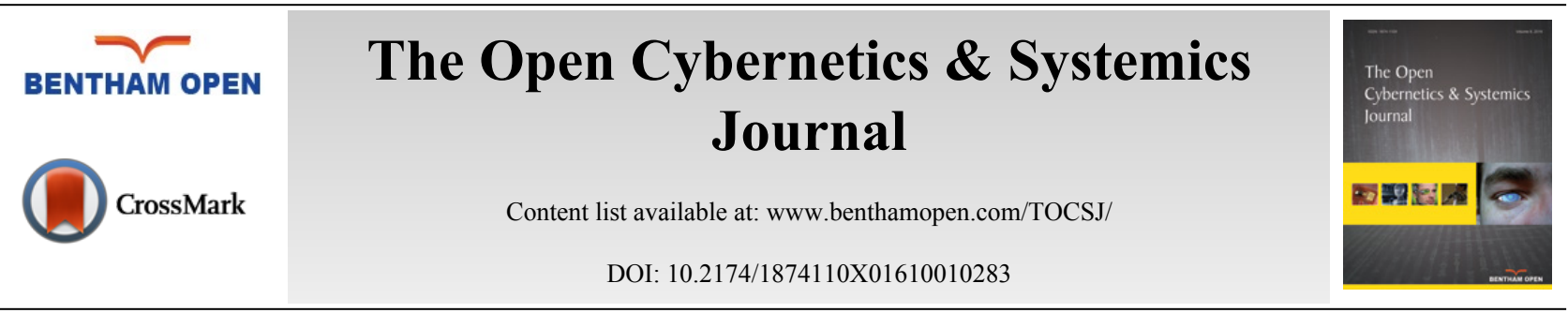

RESEARCH ARTICLE

\title{
Decision-making Method for Clay-brick Selection Based on Subtraction Operational Aggregation Operators of Intuitionistic Fuzzy Values
}

\author{
Zhikang Lu and Jun Ye* \\ Department of Electrical and Information Engineering, Shaoxing University, 508 Huancheng West Road, Shaoxing, \\ Zhejiang Province 312000, P.R. China
}

\begin{abstract}
The subtraction operation of intuitionistic fuzzy sets (IFSs) has been scarcely used for practical applications since it was introduced. Therefore, it is necessary to propose an aggregation operator based on the subtraction operation of IFSs for engineering applications. Then, clay-brick selection is an important decision-making problem for better building construction. To handle the decision-making problem based on the subtraction operation of IFSs in an intuitionistic fuzzy environment, this paper firstly introduces an intuitionistic fuzzy subtraction operational weighted arithmetic averaging (IFSOWAA) operator and investigates its properties. Then, we propose the IFSOWAA operator-based decision-making method as a supplement for existing decision-making methods under an intuitionistic fuzzy environment. Finally, an actual example about a clay-brick selection problem is provided to show the applicability and effectiveness of the proposed method.
\end{abstract}

Keywords: Clay-brick selection, Decision making, Intuitionistic fuzzy set, Intuitionistic fuzzy subtraction operational weighted arithmetic averaging (IFSOWAA) operator, Subtraction operation.

\section{INTRODUCTION}

Multiple attribute decision-making problems are usually to find the most satisfactory alternative from all the feasible alternatives. Owing to the fuzziness of human thinking and cognition about complex decision-making problems, it is difficult to express the attribute values by crisp numbers. Then, a fuzzy set introduced by Zadeh [1] can express fuzzy information in real world. After that, Atanassov [2] considered the non-membership degree and presented an intuitionistic fuzzy set (IFS) as a generalization of the fuzzy set. IFS is composed of a membership degree and a nonmembership degree to describe vague and incomplete information. Therefore, IFS is a very useful tool for dealing with fuzziness and uncertainty in decision-making problems. Many methods have been developed to solve the complex multiple attribute decision-making problems with the IFS information [3 - 26]. As a supplement of basic operational laws over IFSs, Atanassov and Riecan [27] and Chen [28] introduced the subtraction and division operations over IFSs. However, the subtraction and division operations over IFSs are scarcely applied in science and engineering fields since they were presented. Therefore, it is necessary to propose some aggregation operators based on the subtraction and division operations of IFSs for engineering applications.

Clay-brick selection is an important decision-making problem for better building construction. To construct a building, a traditional selection method for clay-bricks provided from various brick fields is to select clay-bricks roughly based on their color, size, and total cost, without considering other quality factors of clay-bricks. In this case, the building construction may produce some dangerous problems regarding low quality clay-bricks. Therefore, it is

\footnotetext{
* Address correspondence to this author at the Department of Electrical and Information Engineering, Shaoxing University, 508 Huancheng West Road, Shaoxing, Zhejiang Province 312000, P.R. China; Tel: +86-575-88327323; E-mail: yehjun@aliyun.com
} 
necessary to formulate a scientific selection method. In order to select the most suitable brick to construct a building, we have to consider the solidity, color, size and shape, strength, cost of brick etc. as their evaluation indices (attributes) [29, 30]. Hence, some researchers have proposed decision-making methods for clay-brick selection problems under intuitionistic fuzzy and single-valued neutrosophic environments [29, 30].

Since existing various intuitionistic fuzzy aggregation operators cannot handle the information aggregation of the intuitionistic fuzzy subtraction operation and existing subtraction operation of intuitionistic fuzzy values (IFVs), which are basic elements in IFSs, lacks the practical applications, this paper presents an intuitionistic fuzzy subtraction operational weighted arithmetic averaging (IFSOWAA) operator and its decision-making method as a supplement of existing decision-making methods, and then applies the IFSOWAA operator-based decision-making method to the decision-making problem of clay-brick selection under an intuitionistic fuzzy environment.

The remainder of this paper is structured as follows. Section 2 reviews some basic knowledge of IFSs and operations of IFVs. Section 3 proposes an IFSOWAA operator based on the subtraction operation of IFVs and investigates its properties. In Section 4, a multiple attribute decision-making method is developed based on the IFSOWAA operator. In Section 5, an actual example about a clay-brick selection problem is provided to show the applicability and effectiveness of the proposed method. Some conclusions and future research are discussed in Section 6.

\section{SOME BASIC KNOWLEDGE OF IFSS AND OPERATIONS OF IFVS}

Atanassov [2] extended fuzzy set to IFS and introduced its definition.

Definition 1 [2]. Let $X$ be a universal of discourse. An IFS $N$ in $X$ is characterized by a membership function $u_{N}(x)$, a non-membership function $v_{N}(x)$, where the values of the two functions $u_{N}(x)$ and $v_{N}(x)$ are real numbers in the interval [0, 1], such that $u_{N}(x) \in[0,1]$ and $v_{N}(x) \in[0,1]$ and $0 \leq u_{N}(x)+v_{N}(x) \leq 1$. Thus, an IFS $N$ is denoted by the mathematical symbol:

Then,

$$
N=\left\{\left\langle x, u_{N}(x), v_{N}(x)\right\rangle \mid x \in X\right\} .
$$

the intuitionistic index (hesitancy) is represented as $m_{N}(x)=1-u_{N}(x)-v_{N}(\mathrm{x})$ and $m_{N}(x) \epsilon[0,1]$ for $x \epsilon X$. For convenience, a basic element $\left\langle x, u_{N}(x), v_{N}(x)\right\rangle$ in an IFS $N$ is denoted by $\left.a=<u_{a}, v_{a}\right\rangle$ for short, which is called IFV [4].

Let $a=\left\langle u_{a}, v_{a}\right\rangle$ and $b=\left\langle u_{b}, v_{b}\right\rangle$ be two IFVs, then there are the following relations [2]:

(1) $a^{c}=\left\langle v_{a}, u_{a}\right\rangle$ (complement of $\left.a\right)$;

(2) $a \leq b$ if and only if $u_{a} \leq u_{b}$ and $v_{a} \geq v_{b}$;

(3) $a=b$ if and only if $u_{a}=u_{b}$ and $v_{a} \quad v_{b}$

After that, the basic operational laws of the two IFVs $a=\left\langle u_{a}, v_{a}\right\rangle$ and $b=\left\langle u_{b}, v_{b}\right\rangle$ are introduced as follows [7]:

(1) $a+b=\left\langle u_{a}+u_{b}-u_{a} u_{b}, v_{a} v_{b}\right\rangle$;

(2) $a \times b=\left\langle u_{a} u_{b}, v_{a}+v_{b}-v_{a} v_{b}\right\rangle$;

(3) $\rho a=\left\langle 1-\left(1-u_{a}\right)^{\rho}, v_{a}^{\rho}\right\rangle$ for $\rho>0$;

(4) $a^{\rho}=\left\langle u_{a}^{\rho}, 1-\left(1-v_{a}\right)^{\rho}\right\rangle$ for $\rho>0$.

For any IFV $a=<u_{a}, v_{a}>$ its score and accuracy functions [31, 32] are introduced, respectively, as follows: 


$$
\begin{gathered}
s(a)=u_{a}-v_{a}, \quad s(a) \in[-1,1], \\
h(a)=u_{a}+v_{a}, \quad h(a) \in[0,1] .
\end{gathered}
$$

Definition $2[4,7]$. Let $a=\left\langle u_{a}, v_{a}\right\rangle$ and $b=\left\langle u_{b}, v_{b}\right\rangle$ be two IFVs, then according to the score values of $s(a)$ and $s(b)$ and the accuracy degrees of $h(a)$ and $h(b)$, there are the following relations:

(1) If $s(a)<s(b)$, then $a<b$;

(2) If $s(a)=s(b)$ and $h(a)<h(b)$, then $a<b$;

(3) If $s(a)=s(b)$ and $h(a)=h(b)$, then $a=b$.

Let $a_{j}=\left\langle u_{a_{j}}, v_{a_{j}}\right\rangle(j=1,2, \ldots, n)$ be a collection of IFVs, then the following intuitionistic fuzzy weighted arithmetic averaging (IFWAA) operator [7] are introduced as follows:

$$
\operatorname{IFWAA}\left(a_{1}, a_{2}, \ldots, a_{n}\right)=\sum_{j=1}^{n} w_{j} a_{j}=\left\langle 1-\prod_{j=1}^{n}\left(1-u_{a_{j}}\right)^{w_{j}}, \prod_{j=1}^{n}\left(v_{a_{j}}\right)^{w_{j}}\right\rangle,
$$

where $w_{j}(j=1,2, \ldots, n)$ is the weight of $a_{j}(j=1,2, \ldots, n)$ with $w_{j} \in[0,1]$ and $\sum_{j=1}^{n} w_{j}=1$.

\section{SUBTRACTION OPERATIONAL WEIGHTED AGGREGATION OPERATOR OF IFVS}

Based on the subtraction operation over IFVs, this section proposes its aggregation operator.

Definition 3. Let $a=\left\langle u_{a}, v_{a}\right\rangle$ and $b=\left\langle u_{b}, v_{b}>\right.$ be two IFVs, then the subtraction operation of the IFVs $a$ and $b$ is defined as follows [27, 28]:

$$
c=a-b=\left\langle u_{c}, v_{c}\right\rangle=\left\langle\frac{u_{a}-u_{b}}{1-u_{b}}, \frac{v_{a}}{v_{b}}\right\rangle \text {, if } a \geq b, u_{b} \neq 1, v_{b} \neq 0, u_{a} v_{b}-u_{b} v_{a} \leq v_{b}-v_{a} .
$$

Based on the basic operational laws of IFVs, we introduce the following theorem:

Theorem 1. Let $a=<u_{a}, v_{a}>$ and $b=<u_{b}, v_{b}>$ be two IFVs, $\rho>0$. Then, there are the following operational laws of $(a-b)$ :

$$
\begin{aligned}
& \rho(a-b)=\left\langle 1-\left(1-\frac{u_{a}-u_{b}}{1-u_{b}}\right)^{\rho},\left(\frac{v_{a}}{v_{b}}\right)^{\rho}\right\rangle, \text { if } a \geq b, u_{b} \neq 1, v_{b} \neq 0, u_{a} v_{b}-u_{b} v_{a} \leq v_{b}-v_{a} . \\
& (a-b)^{\rho}=\left\langle\left(\frac{u_{a}-u_{b}}{1-u_{b}}\right)^{\rho}, 1-\left(1-\frac{v_{a}}{v_{b}}\right)^{\rho}\right\rangle, \text { if } a \geq b, u_{b} \neq 1, v_{b} \neq 0, u_{a} v_{b}-u_{b} v_{a} \leq v_{b}-v_{a} .
\end{aligned}
$$

Obviously, Eqs. (5) and (6) are true according to the basic operational laws of IFVs.

Let $a_{j}=\left\langle u_{a_{j}}, v_{a_{j}}\right\rangle$ and $b_{j}=\left\langle u_{b_{j}}, v_{b_{j}}\right\rangle \quad(j=1,2, . . n) \quad$ be two collections of IFVs and $c_{j}=a_{j}-b_{j}=\left\langle u_{F_{j}}, v_{F_{j}}\right\rangle(j=1,2, \ldots, n)$ be a collection of $c_{j}$. Based on the intuitionistic fuzzy weighted arithmetic averaging aggregation operator of Eq. (3) and Theorem 1, if these conditions $a_{j} \leq b_{j}, u_{b} \neq 1, v_{b} \neq 0, u_{a}, v_{b}-u_{b}, v_{a j} \leq v_{b}-v_{a_{j}}$ are satisfied, we can introduce the intuitionistic fuzzy subtraction operational weighted arithmetic averaging (IFSOWAA) operator: 


$$
\begin{aligned}
& \operatorname{IFSOWAA}\left(c_{1}, c_{2}, \ldots, c_{n}\right)=\sum_{j=1}^{n} w_{j} c_{j}=\sum_{j=1}^{n} w_{j}\left(a_{j}-b_{j}\right) \\
& =\left\langle 1-\prod_{j=1}^{n}\left(1-\frac{u_{a_{j}}-u_{b_{j}}}{1-u_{b_{j}}}\right)^{w_{j}}, \prod_{j=1}^{n}\left(\frac{v_{a_{j}}}{v_{b_{j}}}\right)^{w_{j}}\right\rangle
\end{aligned}
$$

where $w_{j}(j=1,2, \ldots, n)$ is the weight of $c_{j}=a_{j}-b_{j}(j=1,2, \ldots, n)$ with $w_{j} \in[0,1]$ and $\sum_{j=1}^{n} w_{j}=1$.

Especially when $w_{j}=1 / \mathrm{n}(j=1,2, \ldots, n)$ the IFSOWAA operator is degenerated to the intuitionistic fuzzy subtraction operational arithmetic averaging operator.

Based on the properties of the IFWAA operator [7], it is obvious that the IFSOWAA operator also satisfy the properties of idempotency, boundedness and monotonicity:

(1) Idempotency:

If $c_{j}=c$ for $j=1,2, \ldots, n$, then there is $\operatorname{IFSOWAA}\left(c_{1}, c_{2}, \cdots, c_{n}\right)=\sum_{j=1}^{n} w_{j} c_{j}=c$.

(2) Boundedness:

If $C_{\text {min }}=\min \left(C_{1}, C_{2}, \ldots, C_{n}\right)$ and $C_{\max }=\max \left(C_{1}, C_{2}, \ldots, C_{n}\right)$ for $j=1,2, \ldots, n$, then there is $c_{\min } \leq \operatorname{IFSOWAA}\left(c_{1}, c_{2}, \cdots, c_{n}\right) \leq c_{\max } \cdot$

(3) Monotonicity:

If $c_{j} \leq c_{j}^{*}$ for $j=1,2, \ldots, n$, then there is $\operatorname{IFSOWAA}\left(c_{1}, c_{2}, \cdots, c_{n}\right) \leq \operatorname{IFSOWAA}\left(c_{1}^{*}, c_{2}^{*}, \cdots, c_{n}^{*}\right)$.

\section{DECISION-MAKING METHOD BASED ON THE IFSOWAA OPERATOR}

In this section, we present a handling method for multiple attribute decision-making problems based on the IFSOWAA operator.

In a multiple attribute decision-making problem, we suppose that $T=\left\{T_{1}, T_{2}, \ldots, T_{m}\right\}$ be a set of alternatives and $M$ $=\left\{M_{1}, M_{2}, \ldots, M_{n}\right\}$ be a set of attributes. The weight of each attribute $M_{j}(j=1,2, \ldots, n)$ is considered as $w_{j}$, satisfying $w_{j} \in[0,1]$ and $\sum_{j=1}^{n} w_{j}=1$. Then, the characteristic of each alternative $T_{i}(i=1,2, \ldots, m)$ with respect to each attribute $M_{j}(j=1,2, \ldots, n)$ is evaluated by the decision-maker and the evaluation values are expressed by the IFV $a_{i j}=\left\langle u_{i j}, v_{i j}\right\rangle$, where $0 \leq u_{i j}+v_{i j} \leq 1, \quad u_{i j} \geq 0, \quad v_{i j} \geq 0 \quad(j=1,2, \ldots, n ; i=1,2, \ldots, m)$, and then $u_{i j} \in[0,1]$ indicates the degree that the alternative $T_{i}$ is satisfactory to the attribute $M_{j}$ and $v_{i j} \in[0,1]$ indicates the degree that the alternative $T_{i}$ is unsatisfactory to the attribute $M_{j}$. Therefore, we can establish an IFV decision matrix $D=\left(a_{i j}\right)_{m \times n}$.

As for the multiple attribute decision-making problem, we propose a decision-making method, which is described by the following steps:

Step 1. Based on the IFV decision matrix $D=\left(a_{i j}\right)_{m \times n}$, the $j$-th IFV positive ideal solution can be determined $a_{j}^{+}=\left\langle u_{j}^{+}, v_{j}^{+}\right\rangle=\left\langle\max _{i}\left(u_{i j}\right), \min _{i}\left(v_{i j}\right)\right\rangle(j=1,2, \ldots, n)$ and the $j$-th IFV negative ideal solution can be determined by $a_{j}^{-}=\left\langle u_{j}^{-}, v_{j}^{-}\right\rangle=\left\langle\min _{i}\left(u_{i j}\right), \max _{i}\left(v_{i j}\right)\right\rangle(j=1,2, \ldots, n)$. Thus they are constructed as both the ideal alternative $M^{+}=\left\{a_{1}^{+}, a_{2}^{+}, \ldots, a_{n}^{+}\right\}$and the non-ideal alternative $M^{-}=\left\{a_{1}, a_{2}, \ldots, a_{n}^{+}\right\}$.

Step 2. According to Eq. (7), two collective values $C_{i}^{+}$and $C_{i}^{-}(i=1,2, \ldots, m)$ for each alternative $T_{i}(i=1,2, \ldots, m)$ can be calculated by the following IFSOWAA operators: 


$$
\begin{gathered}
c_{i}^{+}=\left\langle u_{c_{j}^{+}}, v_{c_{j}^{+}}\right\rangle=\operatorname{IFSOWAA}\left(c_{i 1}^{+}, c_{i 2}^{+}, \ldots, c_{i n}^{+}\right)=\sum_{j=1}^{n} w_{j} c_{i j}^{+}=\sum_{j=1}^{n} w_{j}\left(a_{j}^{+}-a_{i j}\right) \\
=\left\langle 1-\prod_{j=1}^{n}\left(1-\frac{u_{j}^{+}-u_{i j}}{1-u_{i j}}\right)^{w_{j}}, \prod_{j=1}^{n}\left(\frac{v_{j}^{+}}{v_{i j}}\right)^{w_{j}}\right\rangle \\
c_{i}^{-}=\left\langle u_{c_{j}^{-}}, v_{c_{j}^{-}}\right\rangle=\operatorname{IFSOWAA}\left(c_{i 1}^{-}, c_{i 2}^{-}, \ldots, c_{i n}^{-}\right)=\sum_{j=1}^{n} w_{j} c_{i j}^{-}=\sum_{j=1}^{n} w_{j}\left(a_{i j}-a_{j}^{-}\right) \\
=\left\langle 1-\prod_{j=1}^{n}\left(1-\frac{u_{i j}-u_{j}^{-}}{1-u_{j}^{-}}\right)^{w_{j}}, \prod_{j=1}^{n}\left(\frac{v_{i j}}{v_{j}^{-}}\right)^{w_{j}}\right\rangle
\end{gathered}
$$

Step 3. We calculate the values of $H\left(C_{i}^{+}\right)$and $H\left(C_{i}^{-}\right)(i=1,2, \ldots, m)$ by the hybrid functions of the score and accuracy functions with a real parameter $0 \leq \rho \leq 1$ :

$$
\begin{array}{ll}
H\left(c_{i}^{+}\right)=\rho\left(1+u_{c_{i}^{+}}-v_{c_{i}^{+}}\right) / 2+(1-\rho)\left(u_{c_{i}^{+}}+v_{c_{i}^{+}}\right), & H\left(c_{i}^{+}\right) \in[0,1], \\
H\left(c_{i}^{-}\right)=\rho\left(1+u_{c_{i}^{-}}-v_{c_{i}^{-}}\right) / 2+(1-\rho)\left(u_{c_{i}^{-}}+v_{c_{i}^{-}}\right), \quad H\left(c_{i}^{-}\right) \in[0,1] .
\end{array}
$$

Step 4. The relative closeness degree of each alternative with respect to the ideal alternative $(i=1,2, \ldots, m)$ is calculated by:

$$
R_{i}=\frac{H\left(c_{i}^{-}\right)}{H\left(c_{i}^{-}\right)+H\left(c_{i}^{+}\right)} \text {for } R_{i} \in[0,1] \text {, }
$$

Obviously, the larger value of $R_{i}$ reveals that the alternative is closer to the ideal alternative and farther from the non-ideal alternative simultaneously. Therefore, all the alternatives can be ranked by the values of $R_{i}(i=1,2, \ldots, m)$ in a descending order. The alternative with the largest value is the best choice.

Step 5. End.

\section{ACTUAL EXAMPLE OF CLAY-BRICK SELECTION}

In this section, an actual example about a clay-brick selection problem (adapted from [30]) in a construction company is provided under an intuitionistic fuzzy environment to demonstrate the applicability and effectiveness of the IFSOWAA operator-based multiple attribute decision-making method in realistic scenarios.

For constructing a building, a construction company needs to select the four types of clay-bricks, which are provided from various brick fields, as a set of alternatives $T=\left\{T_{1}, T_{2}, T_{3}, T_{4}\right\}$. To select the most suitable brick for constructing a building, it is necessary to evaluate the four types of clay-bricks by the six attributes of clay-bricks obtained from experts' opinions [30]: (1) $M_{1}$ is solidity, (2) $M_{2}$ is color, (3) $M_{3}$ is size and shape, (4) $M_{4}$ is strength, (5) $M_{5}$ is cost, (6) $M_{6}$ is carrying cost. The weight vector of the six attributes is given by $\boldsymbol{w}=(0.275,0.175,0.2,0.1,0.05$, 0.2). Experts or decision makers are required to evaluate the four possible alternatives under the above six attributes by suitability judgments.

To indicate the evaluation of an alternative $T_{i}(i=1,2,3,4)$ with respect to an attribute $M_{j}(j=1,2, \ldots, 6)$, it can be obtained from the questionnaire or score law of domain experts. For example, when we ask the opinion of an expert about an alternative $T_{1}$ with respect to an attribute $M_{1}$, he/she may say that the possibility in which the statement is suitable is 0.7 and the statement is unsuitable is 0.2 . By the intuitionistic fuzzy notation, it can be expressed as $a_{11}=\langle 0.7,0.2\rangle$. Similarly, when the four possible alternatives with respect to the above six attributes are evaluated by 
the expert, based on [30] we can construct the following IFV decision matrix:

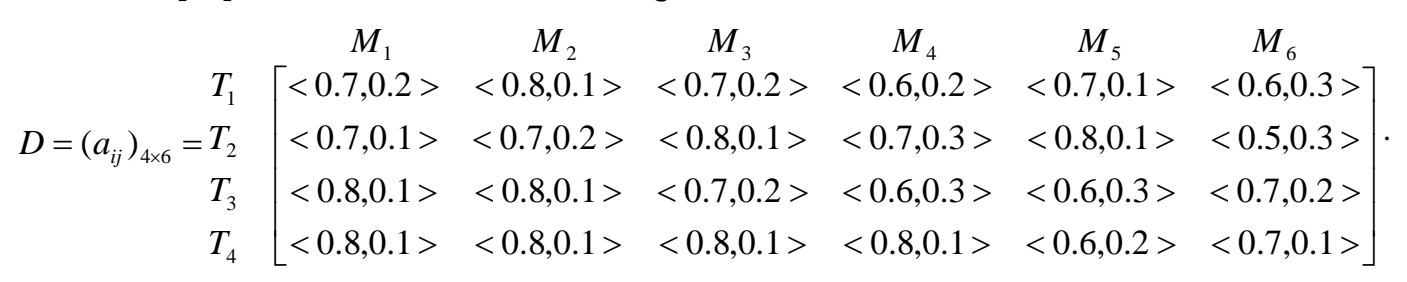

In the decision-making problem of the clay-brick selection, the proposed decision-making method can be applied and the decision steps are described as follows:

Step 1. By $a_{j}^{+}=\left\langle u_{j}^{+}, v_{j}^{+}\right\rangle=\left\langle\max \left(u_{i j}\right), \min \left(v_{i j}\right)\right\rangle \quad$ and $a_{j}^{-}=\left\langle u_{j}^{-}, v_{j}^{-}\right\rangle=\left\langle\min _{i}\left(u_{i j}\right), \max _{i}\left(v_{i j}\right)\right\rangle \quad(i=1,2,3$, $4 ; j=1,2, \ldots, 6)$ we can determine both the IFV positive ideal solutions in the ideal alternative and the IFV negative ideal solutions in the non-ideal alternative, respectively, as follows:

$$
\begin{aligned}
& M^{+}=\left\{a_{1}^{+}, a_{2}^{+}, a_{3}^{+}, a_{4}^{+}, a_{5}^{+}, a_{6}^{+}\right\} \\
& \quad=\{<0.8,0.1>,<0.8,0.1>,<0.8,0.1>,<0.8,0.1>,<0.8,0.1>,<0.7,0.1>\} \\
& M^{-}=\left\{a_{1}^{-}, a_{2}^{-}, a_{3}^{-}, a_{4}^{-}, a_{5}^{-}, a_{6}^{-}\right\} \\
& \quad=\{<0.7,0.2>,<0.7,0.2>,<0.7,0.2>,<0.6,0.3>,<0.6,0.3>,<0.5,0.3>\}
\end{aligned} .
$$

Step 2. By using Eqs. (8) and (9), we can obtain the two collective values $\mathrm{c}_{\mathrm{i}}^{+}$and $\mathrm{c}_{\mathrm{i}}^{-}(i=1,2,3,4)$ for each alternative $T_{i}(i=1,2,3,4)$ :

$$
\begin{aligned}
& C_{1}^{+}=<0.2880,0.5389>, \quad C_{2}^{+}=<0.2776,0.6371>, C_{3}^{+}=<0.1689,0.6427>\text {, and } c_{4}^{+}=<0.0341,0.9659>; \\
& c_{1}^{-}=\left\langle 0.1219,0.8051>, \quad C_{2}^{-}=<0.1346,0.6810>, C_{3}^{-}=<0.2477,0.6750>\text {, and } c_{4}^{-}=<0.3528,0.4491>\right.
\end{aligned}
$$

Step 3. By applying Eqs. (10) and (11) and taking $\rho=0.5$, we calculate the values of $H\left(\mathrm{C}_{\mathrm{i}}^{+}\right)$and $H\left(\mathrm{C}_{\mathrm{i}}^{-}\right)(i=$ $1,2,3,4)$ :

$$
\begin{aligned}
& H\left(c_{1}^{+}\right)=0.6007, H\left(c_{2}^{+}\right)=0.6175, H\left(c_{3}^{+}\right)=0.5374, \text { and } H\left(c_{4}^{+}\right)=0.5170 \\
& H\left(c_{1}^{-}\right)=0.5427, H\left(c_{2}^{-}\right)=0.5212, H\left(c_{3}^{-}\right)=0.6045 \text {, and } H\left(c_{4}^{-}\right)=0.6269
\end{aligned}
$$

Step 4. By using Eq. (12), we calculate the relative closeness degrees of each alternative with respect to the ideal alternative for $R_{i}(i=1,2,3,4)$ :

$$
R_{1}=0.4746, R_{2}=0.4577, R_{3}=0.5294 \text {, and } R_{4}=0.5480 \text {. }
$$

Since the ranking order of the relative closeness degrees is $R_{4}>R_{3}>R_{1}>R_{2}$, the ranking order of the four alternatives is $T_{4} \succ T_{3} \succ T_{1} \succ T_{2}$. Hence, the best alternative is $T_{4}$.

By a comparison with the decision-making method in [30], although the ranking orders are different, the best alternative is the same result as in [30]. Hence, the decision result of the decision-making method proposed in this paper is suitable. It is obvious that the main advantage of the proposed approach is simpler and more convenient than existing related method in [30].

To further demonstrate the effectiveness and rationality of the proposed method in this paper, we compare the proposed method with the conventional method based on the IFWAA operator introduced in [7] and the score and accuracy functions. By directly using the IFWAA operator of Eq. (3), we can obtain all the collective values of $a_{i}=$ $\operatorname{IFWAA}\left(a_{i 1}, a_{i 2}, a_{i 3}, a_{i 4}, a_{i 5}, a_{i 6}\right)(i=1,2,3,4)$ for each alternative $T_{i}(i=1,2,3,4)$ : 


$$
a_{1}=\langle 0.6954,0.1856\rangle, a_{2}=\langle 0.6998,0.1570\rangle, a_{3}=\langle 0.7390,0.1556\rangle, \text { and } a_{4}=\langle 0.7755,0.1035\rangle .
$$

By applying Eq. (1), we calculate the score values of $s\left(a_{i}\right)$ for each alternative $T_{i}(i=1,2,3,4)$ :

$s\left(a_{1}\right)=0.5098, s\left(a_{2}\right)=0.5428, s\left(a_{3}\right)=0.5834$, and $s\left(a_{4}\right)=0.6719$.

Since the ranking order of the score values is $s\left(a_{4}\right)>s\left(a_{3}\right)>s\left(a_{2}\right)>s\left(a_{1}\right)$, the ranking order of the four alternatives is $T_{4} \succ T_{3} \succ T_{2} \succ T_{1}$. Hence, the best alternative is $T_{4}$.

For the above two decision results with respect to the two decision-making methods based on the IFSOWAA and IFWAA operators, we can see that the two ranking orders of the alternatives only reveal difference between $T_{1}$ and $T_{2}$, while the ranking order $T_{4} \succ T_{3}$ and the best alternative $T_{4}$ are identical. Therefore, the decision-making method proposed in this paper is effective and provides a useful supplement for existing decision-making methods under an IFV environment.

\section{CONCLUSION}

To use the subtraction operation of IFVs for practical applications, this paper presented the IFSOWAA operator for IFVs. Next, we developed a multiple attribute decision-making method based on the IFSOWAA operator. Finally, an actual example about a clay-brick selection problem was provided to demonstrate the applicability and effectiveness of the developed method. However, the proposed decision-making method provides both a useful supplement and another new way for existing decision-making methods under an IFV environment. In the future work, the developed method will be further extended to other fields, such as pattern recognition, image processing and clustering analysis.

\section{CONFLICT OF INTEREST}

The authors confirm that this article content has no conflict of interest.

\section{ACKNOWLEDGEMENTS}

Decleared none.

\section{REFERENCES}

[1] L.A. Zadeh, "Fuzzy sets", Inf. Control, vol. 8, pp. 338-356, 1965. [http://dx.doi.org/10.1016/S0019-9958(65)90241-X]

[2] K.T. Atanassov, "Intuitionistic fuzzy set", Fuzzy Sets Syst., vol. 20, pp. 87-96, 1986 [http://dx.doi.org/10.1016/S0165-0114(86)80034-3]

[3] D.F. Li, "Some measures of dissimilarity in intuitionistic fuzzy structures", J. Comput. Syst. Sci., vol. 68, pp. 115-122, 2004. [http://dx.doi.org/10.1016/j.jcss.2003.07.006]

[4] Z.S. Xu, and R.R. Yager, "Some geometric aggregation operators based on intuitionistic fuzzy sets", Int. J. Gen. Syst., vol. 35, pp. 417-433, 2006 [http://dx.doi.org/10.1080/03081070600574353]

[5] L. Lin, X.H. Yuan, and Z.Q. Xia, "Multicriteria fuzzy decision-making methods based on intuitionistic fuzzy sets", J. Comput. Syst. Sci., vol. 73, pp. 84-88, 2007.

[http://dx.doi.org/10.1016/j.jcss.2006.03.004]

[6] H.W. Liu, and G.J. Wang, "Multi-attribute decision-making methods based on intuitionistic fuzzy sets", Eur. J. Oper. Res., vol. 179, pp. 220-233, 2007. [http://dx.doi.org/10.1016/j.ejor.2006.04.009]

[7] Z.S. Xu, "Intuitionistic fuzzy aggregation operators", IEEE Trans. Fuzzy Syst., vol. 15, pp. 1179-1187, 2007. [http://dx.doi.org/10.1109/TFUZZ.2006.890678]

[8] Z.S. Xu, "Some similarity measures of intuitionistic fuzzy sets and their applications to multiple attribute decision making", Fuzzy Optim. Decis. Making, vol. 6, pp. 109-121, 2007. [http://dx.doi.org/10.1007/s10700-007-9004-z]

[9] D.F. Li, "Extension of the LINMAP for multi-attribute decision making under Atanassov's intuitionistic fuzzy environment", Fuzzy Optim. Decis. Making, vol. 7, pp. 7-34, 2008.

[http://dx.doi.org/10.1007/s10700-007-9022-x]

[10] Z.S. Xu, and R.R. Yager, "Dynamic intuitionistic fuzzy multi-attribute decision making", Int. J. Approx. Reason., vol. 48, pp. 246-262, 2008. [http://dx.doi.org/10.1016/j.ijar.2007.08.008] 
[11] G.W. Wei, "Maximizing deviation method for multiple attribute decision making in intuitionistic fuzzy setting", Knowl. Base. Syst., vol. 21, pp. 833-836, 2008. [http://dx.doi.org/10.1016/j.knosys.2008.03.038]

[12] Z.W. Gong, L.S. Li, F.X. Zhou, and T.X. Yai, "Goal programming approaches to obtain the priority vectors from the intuitionistic fuzzy preference relations", Comp. Indus. Engi, vol. 57, pp. 1187-1193, 2009. [http://dx.doi.org/10.1016/j.cie.2009.05.007]

[13] G.W. Wei, "GRA method for multiple attribute decision making with incomplete weight information in intuitionistic fuzzy setting", Knowl. Base. Syst., vol. 23, pp. 243-247, 2010.

[http://dx.doi.org/10.1016/j.knosys.2010.01.003]

[14] G.W. Wei, "Some induced geometric aggregation operators with intuitionistic fuzzy information and their application to group decision making', Appl. Soft Comput., vol. 10, pp. 423-431, 2010. [http://dx.doi.org/10.1016/j.asoc.2009.08.009]

[15] Z.S. Xu, and H. Hu, "Projection models for intuitionistic fuzzy multiple attribute decision making", Int. J. Inf. Technol. Decis. Mak, vol. 9, no. 2, pp. 267-280, 2010.

[http://dx.doi.org/10.1142/S0219622010003816]

[16] J. Ye, "Fuzzy decision-making method based on the weighted correlation coefficient under intuitionistic fuzzy environment", Eur. J. Oper. Res., vol. 205, pp. 202-204, 2010.

[http://dx.doi.org/10.1016/j.ejor.2010.01.019]

[17] J. Ye, "Multiple attribute group decision-making methods with completely unknown weights in intuitionistic fuzzy setting and interval-valued intuitionistic fuzzy setting", Group Decis. Negot., vol. 22, no. 2, pp. 173-188, 2013. [http://dx.doi.org/10.1007/s10726-011-9255-5]

[18] S.P. Wan, and D.F. Li, "Atanassov's intuitionistic fuzzy programming method for heterogeneous multiattribute group decision making with Atanassov's intuitionistic fuzzy truth degrees", IEEE Trans. Fuzzy Syst., vol. 22, no. 2, pp. 300-312, 2014. [http://dx.doi.org/10.1109/TFUZZ.2013.2253107]

[19] S.P. Wan, F. Wang, L.L. Lin, and J.Y. Dong, "An intuitionistic fuzzy linear programming method for logistics outsourcing provider selection", Knowl. Base. Syst., vol. 82, pp. 80-94, 2015. [http://dx.doi.org/10.1016/j.knosys.2015.02.027]

[20] J. Ye, "Similarity measures of intuitionistic fuzzy sets based on cosine function for the decision making of mechanical design schemes", $J$. Intell. Fuzzy Syst., vol. 30, pp. 151-158, 2016. [http://dx.doi.org/10.3233/IFS-151741]

[21] S.P. Wan, F. Wang, and J.Y. Dong, "A novel group decision making method with intuitionistic fuzzy preference relations for RFID technology selection", Appl. Soft Comput., vol. 38, pp. 405-422, 2016. [http://dx.doi.org/10.1016/j.asoc.2015.09.039]

[22] S.P. Wan, F. Wang, and J.Y. Dong, "A novel risk attitudinal ranking method for intuitionistic fuzzy values and application to MADM", Appl. Soft Comput., vol. 40, pp. 98-112, 2016. [http://dx.doi.org/10.1016/j.asoc.2015.11.022]

[23] G.L. Xu, S.P. Wan, F. Wang, J.Y. Dong, and Y.F. Zeng, "Mathematical programming methods for consistency and consensus in group decision making with intuitionistic fuzzy preference relations", Knowl. Base. Syst., vol. 98, pp. 30-43, 2016. [http://dx.doi.org/10.1016/j.knosys.2015.12.007]

[24] J. Xu, S.P. Wan, and J.Y. Dong, "Aggregating decision information into Atanassov's intuitionistic fuzzy numbers for heterogeneous multiattribute group decision making", Appl. Soft Comput., vol. 41, pp. 331-351, 2016. [http://dx.doi.org/10.1016/j.asoc.2015.12.045]

[25] H. Garg, "Some series of intuitionistic fuzzy interactive averaging aggregation operators", Springerplus, vol. 5, no. 1, p. 999, 2016. [http://dx.doi.org/10.1186/s40064-016-2591-9] [PMID: 27441128]

[26] H. Garg, "Generalized intuitionistic fuzzy interactive geometric interaction operators using Einstein t-norm and t-conorm and their application to decision making", Comp. Indus. Engi., vol. 101, pp. 53-69, 2016. [http://dx.doi.org/10.1016/j.cie.2016.08.017]

[27] K.T. Atanassov, and B. Riecan, "On two operations over intuitionistic fuzzy sets", J. Appl. Math. Stat. Info, vol. 2, pp. 145-148, 2006.

[28] T.Y. Chen, "Remarks on the subtraction and division operations over intuitionistic fuzzy sets and interval-valued fuzzy sets", Int. J. Fuzzy Syst., vol. 9, no. 3, pp. 169-172, 2007.

[29] K. Mondal, and S. Pramanik, "Intuitionistic fuzzy multi-criteria group decision making approach to quality clay-brick selection problem based on grey relational analysis", J. Appl. Quant. Methods, vol. 9, no. 2, pp. 35-50, 2014.

[30] K. Mondal, and S. Pramanik, "Neutrosophic decision making model for clay-brick selection in construction field based on grey relational analysis", Neutrosophic Sets Syst., vol. 9, pp. 64-71, 2015.

[31] S.M. Chen, and J.M. Tan, "Handling multi-criteria fuzzy decision making problems based on vague set theory", Fuzzy Sets Syst., vol. 67, pp. 163-172, 1994. [http://dx.doi.org/10.1016/0165-0114(94)90084-1] 
[32] D.H. Hong, and C.H. Choi, "Multi-criteria fuzzy decision-making problems based on vague set theory", Fuzzy Sets Syst., vol. 114, pp. 103-113, 2000.

[http://dx.doi.org/10.1016/S0165-0114(98)00271-1]

(C) Lu and Ye; Licensee Bentham Open

This is an open access article licensed under the terms of the Creative Commons Attribution-Non-Commercial 4.0 International Public License (CC BY-NC 4.0) (https://creativecommons.org/licenses/by-nc/4.0/legalcode), which permits unrestricted, non-commercial use, distribution and reproduction in any medium, provided the work is properly cited. 